\title{
CLIENTE: um novo fator de produção
}

\author{
José Luiz Nunes Fernandes \\ Universidade Federal do Pará \\ jluiz@ufpa.br \\ José Wilson Nunes Fernandes \\ Universidade Federal do Pará \\ jwnf@ufpa.br

\section{Universidade da Amazônia-Unama \\ barbaraadria@yahoo.com.br} \\ Bárbara Ádria Oliveira Faria Fernandes
}

11 Contextus

ISSN 1807-5908

Avaliação: Double Blind Review

Submissão em 30/09/2018.

Aceito em 15/10/2018. 


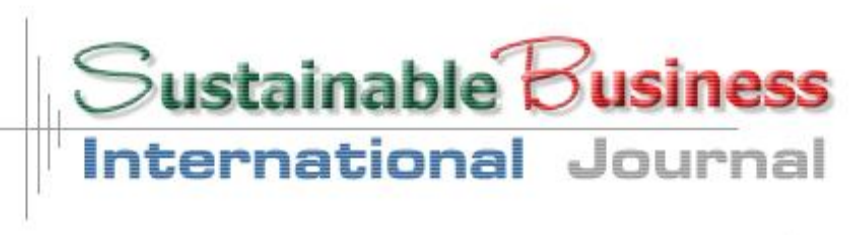

SBIJ87 - JULHO DE 2019 - ISSN 1807-5908

\title{
Resumo
}

Tradicionalmente, os fatores de produção são as matérias-primas, mão de obra e os gastos gerais de fabricação, porém contemporaneamente reconhece-se a presença do cliente no processo produtivo, o que autores convencionaram chamar de cocriação de valor, ou seja, criação conjunta, empresa e cliente. Desse modo, a pesquisa teve como objetivo investigar o correto tratamento dos recursos consumidos por meio da composição dos custos com clientes presentes no processo contemporâneo de produção. Para o alcance do objetivo, buscou-se por meio de estudos bibliográficos e documentais evidenciar estudos reais onde a cocriação de valor está presente e correlacioná-los com a teoria subjacente. A pesquisa concluiu que, quanto à presença dos clientes no processo produtivo, os custeios tradicionais ainda não tiveram a percepção e o tratamento adequado, fato que não acontece com o custeio contemporâneo denominado de Custeio Baseado em Atividades.

Palavras-Chave: Processo Produtivo; Cliente; Cocriação de Valor.

\begin{abstract}
Traditionally the factors of production are the raw materials, labor and overheads of manufacturing, but simultaneously it is recognized the presence of the customer in the productive process, what the authors have agreed to call as a value co-creation. Therefore, the research had as objective to investigate the correct treatment of the resources consumed by means of the composition of costs with customers present in the contemporary process of production. To achieve the objective it was sought by means of bibliographic and documentary studies to demonstrate real studies where the value co-creation is present and correlate them with the underlying theory. The research concluded that, regarding the presence of customers in the productive process, the traditional costs did not have yet the perception and the appropriate treatment, a fact which does not happen with the contemporary costing called activity-based costing.
\end{abstract}

Keywords: Productive Process; Customer; Value co-creation. 


\section{Sustainable Business \\ International Journal}

SBIJ87 - JULHO DE 2019 - ISSN 1807-5908

\section{INTRODUÇÃO}

Martins (2010, p. 24) entende que "desde que duas pessoas resolvam comunicar-se é absolutamente necessário que passem a dar aos objetos, conceitos e ideias o mesmo nome, sob pena de, no mínimo, reduzir-se o nível de entendimento. O que comumente se denomina de mero problema de terminologia, talvez fosse mais bem tratado como magno problema de terminologia".

Por outro lado Dubois, (2003) explica que na maioria das empresas os custos dos bens e serviços passaram a representar a maioria dos custos totais. Nesse sentido, os tradicionais fatores de produção são: matéria-prima, mão de obra e os gastos gerais de fabricação ou Custo Indireto de Fabricação (CIF), mas o mundo contemporâneo dos negócios reconhece que o cliente passou a ter papel chave no processo produtivo, deste modo, o cliente adentrou na produção com o objetivo de criar valor para a empresa.

Castells (2016, p. 73) instiga reflexões quando afirma que "a produção é um processo social complexo, porque cada um dos seus elementos é diferenciado internamente. Assim, a humanidade como produtora coletiva inclui tanto o trabalho como os organizadores da produção, e o trabalho é muito diferenciado e estratificado de acordo com o papel de cada trabalhador no processo produtivo".

Empresas tradicionais como a Procter e Gamble (P\&G), FIAT, Burger King, Construtora Gafisa perceberam a importância do envolvimento do cliente no processo de produção de bens e serviços, porém o desafio para o profissional voltado a apurar, mensurar e 
evidenciar custos é dar o devido tratamento e entendimento ao recurso originado da participação do cliente na produção de bens e serviços.

A participação do cliente no processo produtivo possibilita a cocriação de valor, ou seja, a criação conjunta de valor por meio da empresa e clientes, isso no afã de incremento à competitividade dos negócios. Casas (2014) enfatiza que a cocriação de valor trata de ser assunto extremamente importante no mundo contemporâneo dos negócios.

A relevância do estudo dá-se também pelos entendimentos de Payne, Storbacka e Frow (2008) quando afirmam que pouco se conhece sobre como os consumidores se engajam na cocriação de valor. Ademais Mill (2017, p. 107) alerta que "às vezes o mercado não consegue fornecer um bem ou serviço necessário ou não atribui corretamente os custos". Esse viés, os economistas denominam de falha de mercado.

Nesse sentido, a Contabilidade, que é classificada como ciência social aplicada, necessita entender, mensurar e evidenciar a participação do cliente no processo produtivo, pois esta atuação é realidade no mundo contemporâneo dos negócios, assim cabe ao acadêmico dar o devido tratamento a esse novo e real recurso presente na produção.

A Contabilidade de custos tradicional ensina que os custos são consumo de recursos que incorrem no processo produtivo e, diante disto, o panorama contemporâneo, embora de maneira incipiente, reconhece a participação do cliente nesse processo, portanto o tema além de desafiador é surpreendente ao buscar identificar como fator produtivo o cliente.

Nesse contexto, surge a seguinte questão de pesquisa: $\mathbf{O}$ cliente é um fator produtivo como é a matéria-prima, mão de obra e os gastos gerais? Isto posto, o trabalho tem como propósito investigar o correto reconhecimento dos recursos consumidos por meio da 
composição dos custos, agora com clientes presentes no processo contemporâneo de produção.

\section{REFERENCIAL TEÓRICO}

\subsection{Custos de produção}

Custo é o consumo de recurso para produzir um bem, um serviço ou adquirir uma mercadoria. No ambiente fabril, o custo, como regra, incorre em nível de chão de fábrica. Com o mesmo entendimento, Martins (2010) explica que o recurso torna-se custo no momento da utilização dos fatores de produção, como matéria-prima, mão de obra e gastos gerais, na produção de um bem ou de um serviço.

A ciência que estuda a escassez pode ser estudada sob dupla visão: microeconomia e macroeconomia. O campo de aplicação da microeconomia está voltado para os indivíduos e empresas. Nesse sentido Mill (2017) explica que os fatores produtivos são: (i) a terra que são todos os recursos naturais; (ii) o trabalho, ou mão de obra, que é a pessoa que recebe salário para executar tarefas; e (iii) o capital que é composto por todos os equipamentos utilizados no processo produtivo.

No entendimento contábil, é possível depreender que custo, na visão tradicional, resulta da somatória do consumo da matéria-prima, mão de obra e gastos gerais. Warren et al. (2001) explicam que uma empresa industrial converte matéria-prima em produtos ao usar a mão de obra e as máquinas. Em relação às máquinas, o que é computado nos custos é a depreciação que ocorre em função do uso, ação da natureza ou obsoletismo. 


\section{Sustainable Business \\ International Journal}

SBIJ87 - JULHO DE 2019 - ISSN 1807-5908

A matéria-prima é caracterizada pelos materiais que serão transformados, além das embalagens e outros materiais utilizados no processo produtivo. Por outro lado, a mão de obra é a remuneração do pessoal que trabalha na elaboração do produto ou serviço, bem como os gastos gerais de fabricação ou Custos Indiretos de Fabricação (CIF) são os demais recursos consumidos no processo fabril como o aluguel da fábrica, depreciação de máquinas, seguro do imóvel da fábrica, dentre outros (MARTINS, 2010).

Com entendimento igual ao do autor anterior Atkinson et al. (2015) explicam que, em um sistema de custo de fabricação tradicional, os custos de fabricação são classificados em três grupos: (i) materiais diretos, mão de obra e custos indiretos de fabricação. Os custos de materiais diretos incluem os materiais facilmente alocados a uma unidade de produção e de consequência econômica significativa para o produto final. Por outro lado, a mão de obra é a remuneração do trabalhador que constroem fisicamente uma unidade de produção e os custos indiretos de fabricação são aqueles incorridos pela instalação da produção e que não são custos dos materiais e da mão de obra.

O tipo de informação gerado pelo sistema de custos e a respectiva relevância para ações gerenciais, aliadas ao modo em que os dados são processados para gerar essas informações, é denominado de método de custeio (JIAMBALVO, 2009). Diante disto, custeio significa a maneira ou o modo em que o objeto de custos recebe os custos. De outro modo, custeio é a maneira de direcionar os custos ao que se deseja atribuir ou mensurar, desse modo tem-se o Custeio por Absorção, Custeio Variável, ABC, RKW etc. (MARTINS, 2010).

Para Coelho e Lins (2010) os métodos de custeio foram desenvolvidos na Europa, notadamente na Inglaterra, Itália e Alemanha e, posteriormente, nos Estados Unidos. Neste 
último, os custos fixos não recebiam grande atenção, uma vez que no passado partia-se do pressuposto de que os custos fixos não apresentavam valores representativos e como tal irreal para os dias atuais em função da presença da tecnologia em nível de chão de fábrica, fato que demanda mais custos fixos em face da depreciação dessa tecnologia.

Kulmala et al., (2002) entendem que os métodos de custeio são de fundamental importância para a gestão, tanto em nível estratégico quanto operacional. Slavov, (2013) observa que quanto maior a complexidade da decisão como, por exemplo, vinculada às questões estratégicas, maior será a necessidade de adequação às necessidades das variáveis do método de custeio.

Os custeios tradicionais, como o por Absorção e o Variável, separam os consumos de recursos na área administrativa como despesa e o consumo de recurso incorrido na área da fábrica e voltado à produção como custo e isso denota certa tradição ou conservadorismo. Diante disto, Markantonis et al. (2012) explicam que os custeio tradicionais foram desenvolvidos em um ambiente econômico no qual a mão de obra e os materiais diretos correspondiam a uma grande porção dos custos, sendo válido, portanto, a utilização de bases de rateio baseadas em volume produção para os custos indiretos, que representavam uma pequena porção dos custos.

Quadro 1. Visão tradicional do consumo de recursos

\begin{tabular}{|l|l|}
\hline Área Administrativa - Despesas & Chão de Fábrica - Custos \\
\hline $\begin{array}{l}\text { Aluguel, energia, depreciação de } \\
\text { móveis, salários e encargos, } \\
\text { comissões, juro etc... }\end{array}$ & $\begin{array}{l}\text { Matéria-Prima } \\
\text { Gastos Obra Gerais }\end{array}$ \\
\hline
\end{tabular}

\section{Clientes}

Fonte: Elaborado pelos autores, 2017.

Depreende-se do Quadro 1 que os custeios tradicionais, como a absorção e variável, fazem nítida separação de que as despesas ocorrem fora da área físico-geográfica da fábrica e 
os custos incorrem no nível de chão de fábrica e nesses tipos de custeio não se vislumbra a participação do cliente no processo de transformação.

Nas explicações de Abbas et al. (2012), até a década de 1970 predominava na apuração dos custos a adoção do custeio por absorção que aglutinava os custos predominantes com os materiais diretos e a mão de obra. Porém, a partir dessa década, ocorreram modificações no ambiente econômico e as organizações passaram a investir intensamente em tecnologias, engenharia, marketing, desenvolvimento de produtos, serviços aos clientes e treinamentos, ocorrendo, portanto, aumento significativo nos custos indiretos. Assim, a mão de obra direta e os materiais diretos, até os anos 1970, eram os fatores de produção que predominavam.

Por outro lado, o Custeio Baseado em Atividades (ABC) não vê assim. Dias e Padoveze (2007) explicam que o custeio ABC apropria-se todos os custos e despesas da empresa ao produto mediante análise dos processos e atividades, utilizando-se direcionadores de custos em dois estágios. Nesse conceito, o produto consome atividades e estas consomem recursos. Diante disto, Kaplan e Cooper, (1998) consideram o Custeio Baseado em Atividades como um custeio de vanguarda.

O custeio ABC, nos entendimentos de Jiambalvo (2009) e Martins (2010) é um método de custeio voltado para gestão de custos e aloca aqueles incorridos com base nas atividades desenvolvidas pela organização, rastreando-os por meio de direcionadores de custo e imputando-os aos produtos.

Quadro 2. Custeio ABC

\begin{tabular}{|l|l|l|}
\hline Recursos & Atividades & Objetos de custos \\
\hline Monetários & Compra, produção, venda, estocagem & Produtos, serviços, clientes, restaurante \\
\hline
\end{tabular}




\section{Sustainable Business \\ International Journal}

SBIJ87 - JULHO DE 2019 - ISSN 1807-5908

Fonte: Elaborado pelos autores, 2017.

O Quadro 2 demonstra que no custeio $\mathrm{ABC}$ os recursos são consumidos pelas diversas atividades exercidas pelas empresas como: compra, produção, venda e estocagem, e que os objetos de custos são consumidos pelas atividades da empresa. Esse custeio de vanguarda não separa, para efeito de apurar custos, a área administrativa da área fabril e pode considerar a participação do cliente no processo de produção como componente da atividade produção.

O ABC é um artefato de mensuração de custos, cujo foco engloba os processos, as atividades e os direcionadores de custos. Parte-se do pressuposto de que esse método de custeio não mensura somente produtos, podendo mensurar, também, processos, atividades e outros objetos de custeio (NAKAGAWA, 2012). Depreende-se, desse modo, que o custeio $\mathrm{ABC}$ tem também eficácia estendida além das fronteiras tradicionais das empresas.

É possível destacar que o uso estratégico do custeio $\mathrm{ABC}$ permite responder quanto custam os objetos de custo. Desse modo, o ABC estratégico fornece informações sobre custos dos produtos, dos clientes e dos canais de distribuição (PLEYER; MARX JR., 2000).

Por fim, a eficácia do método do custeio $\mathrm{ABC}$ é posta em "xeque" quando Lockamy e Smith (2000) criticam o uso isolado do custeio ABC e da Gestão Baseada em Atividades $(\mathrm{ABM})$, pois, segundo os pesquisadores, ambos falham no entendimento de como aumentar a satisfação do cliente componente de uma rede.

No panorama de produção, instiga a reflexão do conceito de despesas. Martins (2010) ensina que despesa é um recurso consumido direta ou indiretamente voltado à obtenção de receitas. Iudícibus et al. (2010) explicam que as despesas surgem nas atividades cotidianas das empresas e exemplificam-nas como os salários do pessoal administrativo e a depreciação de 
móveis e utensílios. As despesas são reconhecidas na apuração do resultado das empresas quando surge um decréscimo que possa ser determinado em bases confiáveis, nos futuros benefícios econômicos provenientes da diminuição de um ativo ou aumento de um passivo (IUDÍCIBUS et al., 2010).

A definição de despesa desenvolvida pelo Financial Accounting Standards Board (FASB) avança quando expressa que despesa é a saída ou outro uso de ativos ou ocorrência de passivos (ou ambos) para a entrega ou produção de bens, a prestação de serviços, ou a execução de outras atividades que representam as operações principais em andamento da entidade.

A sinergia entre despesa e a consecução de receita é estudada quando Coelho e Lins (2010, p. 50) explicam que "qualquer gasto caracterizado como despesa não é realizado sem sentido. Julga-se que é importante, ou mesmo fundamental, a existência daquela despesa para que mais à frente tenha-se a possibilidade de gerar receitas".

No panorama do presente estudo, outro recurso consumido merecedor de estudos é o voltado à pesquisa e desenvolvimento. Nesse sentido, Iudícibus et al. (2010) orientam que esses gastos devem ser reconhecidos como despesas pelo fato de não possuírem plena garantia de que irão gerar benefícios econômicos futuros para a empresa.

Por outro lado, aproveitar o talento dos clientes, por meio de experiências e conhecimentos que eles possuem, pode ser ação de incremento à competitividade das empresas (BENDAPUDI; LEONE, 2003). Nesse sentido Prahalad e Ramaswamy (2004) relatam que o desejo do consumidor por interação é o que dá origem ao processo da cocriação de valor. 


\section{Sustainable Business \\ International Journal}

SBIJ87 - JULHO DE 2019 - ISSN 1807-5908

\subsection{Cocriação de valor}

Entende-se necessário estimular reflexão sobre o termo "valor" como uma mais valia que o cliente externo percebe. Nessa direção, Porter (1986) afirma que o valor sob a percepção do cliente é originado das diversas atividades exercidas internamente pelas empresas. Magretta (2012, p. 86), ao explicar os entendimentos de Porter sobre cadeia de valor, afirma: "a sequência de atividades realizadas por uma empresa para projetar, produzir, vender, entregar e dar suporte a seus produtos é denominada de cadeia de valor".

Figura 1. Cadeia de Valor

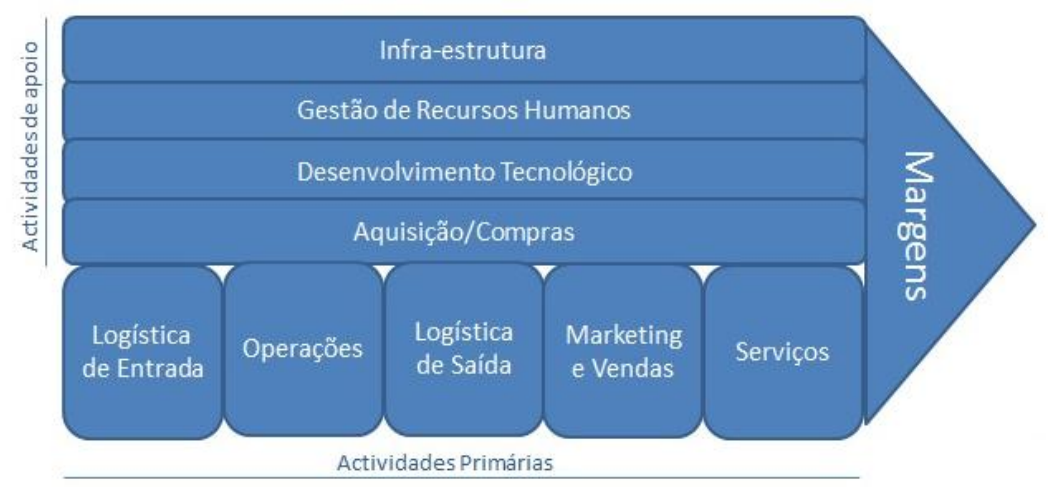

Fonte: Adaptado de Porter, 1986.

A Figura 1, derivada dos entendimentos de Porter (1986), divide a empresa em dois grandes blocos internos de atividades: (i) atividades de apoio - infraestrutura, gestão de RH, desenvolvimento tecnológico, compras etc.; (ii) atividades primárias - logística, produção, marketing e vendas etc. Depreende-se que o cliente, em relação à lógica do raciocínio de Porter desenvolvida na década de 1980, não faz parte da agregação de valor.

A visão tradicional-passada enfatizava que o valor era centralizado e oferecido pela empresa e com olhar endógeno em busca de eficiência e redução de seus custos com a 
intenção de obter maior lucro (PRAHALAD; RAMASWAMY, 2004; VARGO; LUSCH, 2004). Com a evolução da maneira de realizar negócios, os entendimentos de Porter necessitaram mudar e, nesse sentido, surgiu o que hoje se denomina de cocriação de valor.

As empresas ao envolverem clientes no processo produtivo com o objetivo de cocriar valor são capazes de transformar os esforços, habilidades e conhecimentos desses consumidores em vantagens competitivas para si (PAYNE et al., 2008), criando a chance de ficarem evidenciadas no mercado em prol de atingir vantagem competitiva (NAMBISAM; NAMBISAM, 2008; MCCOLL-KENNEDY et al., 2012).

A ideia da participação do cliente no processo de criação de valor não é novidade, porém, nova é a expressão “cocriação de valor”, como participação ativa do consumidor, gerando desempenho e valor superior (PRAHALAD; RAMASWAMY, 2004). Em alguns contextos, a cocriação de valor não é apenas desejada, mas imprescindível à geração de valor.

Entende-se no contexto do referido estudo que o prefixo "co", presente no termo cocriação de valor, tem o sentido de criar de forma conjunta, ou seja, cliente e empresa, portanto, a cocriação de valor direciona as empresas na mudança do foco da oferta de serviço ou produto para a experiência do consumidor (ZAGO; KYOKO, 2013). Nesse viés, Tavares (2016) afirma que, com desenvolvimento organizacional na maneira de pensar e fazer sua gestão, ocorreu o afastamento em relação à forma tradicional de criação de valor, sugerindo que as empresas criem valor e repassem aos seus clientes/consumidores, realizando um esforço conjunto.

No panorama anterior, os custos eram acrescentados aos produtos ou serviços com base nos três tradicionais fatores produtivos: matéria-prima, mão de obra e gastos gerais, 


\section{Sustainable Business \\ International Journal}

SBIJ87 - JULHO DE 2019 - ISSN 1807-5908

porém o panorama contemporâneo privilegia nesse processo o cliente (PRAHALAD; RAMASWAMY, 2004). Mas agora estão predominantemente voltados para a interatividade e para as experiências proporcionadas pelos clientes (GRONROOS; RAVALD, 2011; GRONROOS; VOIMA, 2013).

Nessa direção e no processo produtivo em relação à cocriação de valor, Ramaswamy e Gouillart (2010) destacam a ativa participação dos clientes quando afirmam que estes também são parte integrante no processo de transformação, tendo um papel importante na criatividade investida em busca de melhores experiências, ou seja, os clientes não apenas recebem o produto como participam da elaboração.

Quadro 3. Visão de vanguarda do consumo de recursos

\begin{tabular}{|l|l|}
\hline Área Administrativa - Despesas & Chão de Fábrica - Custos \\
\hline Aluguel, energia, depreciação de & Matéria Prima \\
móveis, salários e encargos, & Mão de obra \\
comissões, juro etc... & Gastos Gerais \\
& Clientes \\
\hline
\end{tabular}

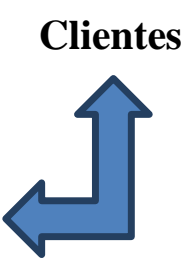

Fonte: Elaborado pelos autores, 2017.

O Quadro 3 demonstra que, no panorama de transformação contemporâneo, a produção de bens e serviços passou a ser composta por novo fator ou elemento que é o cliente, pois esse extrapolou o muro tradicional das empresas e, por meio de sua expertise, passou a participar efetivamente do processo de transformação (RAMASWAMY; GOUILLART, 2010).

Com o mesmo entendimento Tavares (2016) expressa que, atualmente, nota-se uma mudança no comportamento e atitude dos clientes, que passam de uma postura passiva para uma maneira conectada e informada, exigindo uma adaptação das organizações a essa nova postura. 


\section{Sustainable Business \\ International Journal}

SBIJ87 - JULHO DE 2019 - ISSN 1807-5908

A visão contemporânea da presença do cliente no processo produtivo é destacada por Payne et al. (2008), quando entendem que o interesse por parte do cliente é despertado quando a organização expõe um produto ou serviço que mostre diferencial superior aos demais disponíveis no mercado e acrescentam, ainda, que a cocriação de valor é o envolvimento e interação entre organização e clientes em todos os aspectos, desde a criação do produto até o consumo, ou seja, no decorrer de todo o processo (PAYNE et al, 2008).

Diante dos entendimentos de que o cliente deixou de ter ação passiva no processo de transformação, portanto, ultrapassou a fronteira física tradicional que o separava da produção e, desse modo, passando a ação ativa na transformação de bens e serviços, realidade que instiga pesquisa ao vislumbrar possibilidade de considerá-lo como "novo" fator produtivo, é que se evidenciará o método que deu suporte o presente estudo.

\section{PROCESSO METODOLÓGICO}

Entende-se que a metodologia que deu suporte à presente pesquisa é um processo composto por ações sucessivas e crescentes direcionadas ao alcance do objetivo proposto. Nesse sentido, buscou-se incialmente identificar realidade mercadológica que induziu o cliente ao caminho inverso ao tradicional, assim a empresa produzia para atender as necessidades dos clientes externos os quais reconheciam ou não a agregação de valor. $\mathrm{O}$ caminho inverso é o cliente adentrar na empresa e desse modo voltar e romper os muros tradicionais das organizações, como o objetivo de cocriar valor, ou seja, criar valor conjuntamente. 


\section{Sustainable Business \\ International Journal}

SBIJ87 - JULHO DE 2019 - ISSN 1807-5908

Essa realidade induz a repensar os tradicionais fatores produtivos presentes no processo de produção (matéria-prima, mão de obra e gastos gerais de fabricação), pois o mundo contemporâneo dos negócios agora possui novo componente no processo de transformação do produto ou serviço, o cliente.

Diante disto, alicerçou-se teoricamente o presente estudo nos temas voltados aos custos de produção nos moldes tradicionais e não tradicionais, bem como se adicionou nova variável que alicerça a realidade contemporânea no nível de chão de fábrica, o cliente e a consequente cocriação de valor.

Para ratificar a realidade e tentar responder à questão de pesquisa e, como consequência, atingir o objetivo proposto, buscou-se por meio de estudos bibliográficos e documentais (artigos, livros, jornais, dissertações e teses) evidenciar casos reais onde a cocriação de valor está presente, como também está a consequente participação do cliente no processo produtivo.

\section{ANÁLISE DOS RESULTADOS}

Estudos serão descritos no sentido de evidenciar a participação do cliente no processo produtivo e, com isso, serão confrontados com a teoria que alicerça a presente pesquisa com objetivo de dar o devido suporte para a resposta ao problema inicialmente fixado.

$1^{\circ}$ Estudo: Procter e Gamble (P\&G)

A P\&G foi fundada em 1837 por James Gamble e William Procter em Cincinnati, Estados Unidos da América (EUA). Inicialmente, a atividade consistia na produção de sabonetes. Em 1988, a P\&G adquiriu a tradicional empresa Brasileira - Paraense denominada 


\section{Sustainable Business \\ International Journal}

SBIJ87 - JULHO DE 2019 - ISSN 1807-5908

de Perfumarias Phebo S/A que, além da produção de sabonetes, tem em seu mix outros produtos voltados à perfumaria.

Fisk (2006) explica que a $P \& G$ reconheceu que, mesmo focada nos clientes - deixar a roupa mais branca ou tornar fraldas mais absorventes - a empresa percebia a necessidade de melhorar as suas embalagens no sentido de torná-las mais convenientes no armazenamento do espaço doméstico dos clientes, bem como nas prateleiras aos locais de vendas. Grupos focais internos foram constituídos, porém sem resultados positivos. A P\&G percebeu também a necessidade de inovar em produtos, já que na época somente $20 \%$ dos lançamentos da empresa alcançava a meta de retorno sobre o investimento, o momento era preocupante (HUSTON; SAKKAB, 2006).

No panorama ao norte identificado, Huston e Sakkab, (2006) explicam que as vendas estavam estagnadas e as ações reduziram pela metade o valor no período de um ano e, ainda, a dificuldade em lidar com excesso de dados originados de pesquisas quantitativas induziu ao direcionamento de utilizar insights por meio de análises qualitativas.

Em busca de soluções, a P\&G criou o modelo de inovação Conect and Develop onde, por meio de uma noção clara de identificar e satisfazer às necessidades dos clientes, deste modo a ordem foi "o cliente é quem manda". Desse modo, Fisk (2006) explica que antes o produto que era o rei. Mas essa abordagem se inverteu em virtude da necessidade de melhorar os resultados, consequentemente a empresa voltou-se para fora e, em especial, clientes e competidores com o foco de identificar as necessidades de consumo.

O resultado foi surpreendentemente positivo como as listas brancas do creme dental Crest, além de que o design dos produtos foram alterados e o exemplo foram as caixas na 


\section{Sustainable Business \\ International Journal}

SBIJ87 - JULHO DE 2019 - ISSN 1807-5908

forma de sapo como embalagens umedecidas para lenços de bebês. $\mathrm{O}$ resultado fez com que mais de 35\% dos produtos teve participação direta dos clientes. Fisk (2006) finaliza afirmando que o programa Connect and Develop resultou em mais de 250 produtos repaginados incrementando assim as vendas em bilhões de dólares. Nessa direção, as empresas ao envolverem clientes no processo produtivo com o objetivo de cocriar valor, são capazes de transformar os esforços, habilidades e conhecimentos desses consumidores em vantagens competitivas para si (PAYNE et al., 2008).

Depreende-se do fato vivenciado pela $P \& G$ a presença do entendimento de que agora a gestão de processos e produtos está predominantemente voltada para a interatividade e para as experiências proporcionadas pelos clientes (GRONROOS; RAVALD, 2011) \& (GRONROOS; VOIMA, 2013).

Diante disto, a produção de bens e serviços passou a ser composta por novo fator ou elemento que é o cliente, considerando que esse quebrou a barreira tradicional das empresas e, por meio de sua expertise, passou a participar efetivamente do processo de transformação (RAMASWAMY; GOUILLART, 2010).

$2^{\circ}$ Estudo: Fiat Mio

O gerente do Centro de Estilo da Fiat ao participar em 2008 do Salão do Automóvel leu artigo em uma revista alemã especializada na indústria automobilística o qual expressava que as montadoras não davam ouvidos aos clientes. O gerente ficou incomodado com o fato e resolveu criar novo carro-conceito para o salão de 2009 e, de maneira totalmente diferente, onde o cliente iria passar a ser ouvido (CASAS, 2014). 


\section{Sustainable Business \\ International Journal}

SBIJ87 - JULHO DE 2019 - ISSN 1807-5908

A empresa de publicidade e comunicação da Fiat ficou com a responsabilidade de engajar os clientes no processo e denominou o projeto de Fiat Mio. Nesse panorama, a Fiat fixou como objetivo, em relação ao Fiat Mio, desenvolver e apresentar um carro-conceito numa visão inédita na indústria, ou seja, a cocriação de um novo carro para um novo tempo e efetivamente ouvindo os clientes.

No salão do automóvel de 2009, o Fiat Mio possibilitou que a Fiat juntamente com a empresa de publicidade e comunicação ganhassem vários prêmios nas mais diversas áreas, portanto o case Fiat Mio fez história tornando-se marco também no Festival Mundial da Criação em Cannes, França (CASAS, 2014).

O case do Fiat Mio resgata os entendimentos de Payne et al. (2008) quando expressam que o interesse por parte do cliente é despertado à medida que a organização expõe um produto ou serviço que mostre diferencial superior aos demais disponíveis no mercado. Nesse sentido, a cocriação de valor direciona as empresas na mudança do foco da oferta de serviço ou produto para a experiência do consumidor (ZAGO; KYOKO, 2013).

$3^{\circ}$ Estudo: Construtora Gafisa

A Gafisa foi fundada em 1945 na cidade do Rio de Janeiro para atuar no mercado imobiliário. Em 2011, a Gafisa lançou o primeiro projeto de construção de um edifício por meio da cocriação de valor e o denominou de Edifício Colaborativo. A empresa sentiu necessidade de propor ao mercado da construção civil um novo modelo que fosse possível atrair novos clientes por meio de um edifício residencial.

O processo de cocriação de valor usado pela Gafisa foi por meio da internet, deste modo e com a ajuda das redes sociais e da comunicação móvel, passou a consultar e ouvir os 
potenciais clientes e essas ações possibilitaram que os clientes tornassem mais colaborativos. Nesse sentido, Casas (2014) explica que a cocriação implementada pela Gafisa possibilitou a renovação da marca e diferenciação em seu segmento de mercado.

Após um ano do levantamento de ideias e sugestões dos clientes, colhidas por meio da página da Gafisa no Facebook, a empresa obteve como resultado número expressivo de clientes os quais estavam dentre as 40.000 curtidas no Facebook. Diante disto, a cocriação de valor é o envolvimento e interação entre organização e clientes em todos os aspectos, desde a criação do produto até o consumo, ou seja, no decorrer de todo o processo (PAYNE et al., 2008).

A participação do cliente e a consequente cocriação de valor vivenciada pela Gafisa é destacada por Ramaswamy e Gouillart (2010) quando afirmam que a ativa participação dos clientes também é parte integrante no processo de transformação, tendo um papel importante na criatividade investida e da busca de melhores experiências, ou seja, os clientes não apenas recebem o produto como participam da elaboração.

$4^{\circ}$ Estudo: Custos em serviços

O estudo que será descrito refere-se ao serviço prestado por uma academia de ginástica e a participação do cliente na composição dos custos. Nesse sentido evidencia-se que a indústria esportiva está posicionada entre os setores que mais crescem no mundo, sendo US\$ 1,3 trilhões de faturamento em 2009. No Brasil, em 2010, o faturamento por meio das práticas esportivas gerou 1,9\% do PIB brasileiro (TAVARES, 2016).

O mercado competitivo das academias de ginástica localizadas na cidade de São Paulo induziu Tavares (2016) a buscar alternativas para incremento da competividade dessas. Nessa 


\section{Sustainable Business \\ International Journal}

\section{SBIJ87 - JULHO DE 2019 - ISSN 1807-5908}

perspectiva, foi efetuada pesquisa em diferentes academias paulistanas por meio de observação direta, análise de documentos e entrevistas semiestruturadas.

A pesquisa de Tavares (2016) chegou à conclusão de que por meio da experiência única os relacionamentos dos clientes com a academia são fortalecidos. Nesse sentido, a participação do cliente cria chance desses empreendimentos ficarem evidenciados no mercado em prol de atingir vantagem competitiva (NAMBISAM; NAMBISAM, 2008) \& (MCCOLLKENNEDY et al., 2012).

A experiência única não ocorre por meio da diversificação de modalidades e atividades oferecidas pela academia, mas detectou-se que a experiência memorável ocorre por meio do bom atendimento que, conforme as entrevistas com os clientes para a ocorrência de um bom atendimento, é preciso em primeiro lugar o diálogo constante, o acesso às informações, para que os clientes se sintam importantes para a academia.

A pesquisa de Tavares (2016) confirma o entendimento de que a cocriação de valor é o envolvimento e interação entre organização e clientes em todos os aspectos, desde a criação do produto até o consumo, ou seja, no decorrer de todo o processo (PAYNE et al., 2008).

A análise dos estudos com acurácia dos documentos acessados durante o trabalho permitiu estabelecer uma relação segura e consistente entre a literatura e as práticas identificadas nas empresas estudadas. O Quadro 4, em seguida, sintetiza os estudos e os principais resultados.

Quadro 4. Estudos e resultados

\begin{tabular}{|l|l|l|l|}
\hline EMPRESA/PRODUTO & PROBLEMA & RESULTADO & REFER $\hat{E N C I A S ~}$ \\
\hline Procter e Gamble (P\&G) & Necessidade de inovação de & Criou modelo de inovação & Payne et al. ,(2008); \\
& produtos. Vendas & $\begin{array}{l}\text { Conect and Develop, para } \\
\text { estagnadas e as ações } \\
\text { identificar e satisfazer as anroos e Ravald, } \\
\text { reduzidas pela metade. }\end{array}$ & $\begin{array}{l}\text { (2011); Gronroos e e } \\
\text { necessidades dos clientes. O Voima, (2013). }\end{array}$ \\
\hline
\end{tabular}




\section{Sustainable Business \\ International Journal}

SBIJ87 - JULHO DE 2019 - ISSN 1807-5908

\begin{tabular}{|c|c|c|c|}
\hline & & $\begin{array}{lr}\text { resultado foi } \\
\text { surpreendentemente positivo. }\end{array}$ & \\
\hline FIAT: Fiat Mio & $\begin{array}{l}\text { Empresa não ouvia o cliente } \\
\text { no processo de } \\
\text { transformação. }\end{array}$ & $\begin{array}{llr}\text { Engajar os clientes no } & \text { nacesso e denominou o } \\
\text { process } & \\
\text { Projeto de Fiat Mio. Projeto } \\
\text { premiado. }\end{array}$ & $\begin{array}{l}\text { Payne et al.,(2008); } \\
\text { Zago e Kyoko, } \\
(2013) \text {. }\end{array}$ \\
\hline Construtora Gafisa & $\begin{array}{l}\text { Necessidade de propor ao } \\
\text { mercado da construção civil } \\
\text { um novo modelo que fosse } \\
\text { possível atrair novos } \\
\text { clientes por meio de um } \\
\text { edifício residencial. }\end{array}$ & $\begin{array}{l}\text { Por meio da internet e com a } \\
\text { ajuda das redes sociais e da } \\
\text { comunicação } \\
\text { possibilitou que os clientes } \\
\text { se tornassem } \\
\text { colaborativos. }\end{array}$ & $\begin{array}{l}\text { Payne et al.,(2008); } \\
\text { Casas,(2014). }\end{array}$ \\
\hline $\begin{array}{l}\text { Custos em serviços- } \\
\text { Academias de Ginásticas }\end{array}$ & $\begin{array}{l}\text { Fazer frente ao mercado } \\
\text { competitivo. }\end{array}$ & $\begin{array}{l}\text { Por meio da experiência } \\
\text { única, os relacionamentos } \\
\text { dos clientes com a academia } \\
\text { são fortalecidos. }\end{array}$ & $\begin{array}{l}\text { Payne et al. .(2008); } \\
\text { Nambisam } \\
\text { Nambisam, (2008) e } \\
\text { Mccoll-Kennedy et } \\
\text { al.,(2012). }\end{array}$ \\
\hline
\end{tabular}

Fonte: Dados da pesquisa, 2017.

\section{CONCLUSÃO}

O trabalho teve como objetivo identificar se o cliente presente no processo produtivo de bens e serviços é um fator produtivo e para isso alicerçou-se no referencial teórico voltado a custos, custeios e cocriação de valor.

De forma especial, ao abordar os temas voltados aos custeios dos produtos e serviços, a pesquisa identificou que os mesmos podem ser estudados sob a visão de tradicionais, contemporâneos ou de vanguarda, desse modo os tradicionais visualizam custos como o consumo de recursos circunscritos ao ambiente geográfico da fábrica como os custeios por absorção e o direto/variável.

Por outro lado, o custeio de vanguarda ou contemporâneo percebe a empresa na visão horizontal de processo e cadeia de valor, desse modo entende que as atividades relevantes são as que consomem recursos e os objetos de custos - produtos e serviços - consomem as atividades, como por exemplo, o custeio ABC. 
Quanto aos custeios tradicionais, os fatores de produção também são os tradicionais, quais sejam matéria-prima, mão de obra e gastos gerais de fabricação ou CIF, portanto é difícil vislumbrar a figura do cliente, mesmo que com efetiva participação no processo e, portanto, cocriando valor à empresa, compondo assim os custos dos produtos, como custo do período, e voltado à obtenção de receitas aderindo, dessa forma o conceito de despesa.

Já em relação ao custeio $\mathrm{ABC}$, que possui eficácia gerencial e é classificado como custeio de vanguarda ou contemporâneo, a figura do cliente torna-se evidente no processo produtivo e de criação de valor, nesse custeio é possível ver, mensurar e evidenciar o cliente cocriando valor para a entidade econômica e presente no processo de transformação, portanto considerá-lo como fator de produção.

Tem-se a expectativa de que esse estudo instigue novas pesquisas no sentido de que estudiosos do tema se manifestem sobre o entendimento do autor, ratificando ou não o resultado que se chegou e, com isso, possibilitando o avanço do conhecimento da área de custos empresariais em sintonia com as transformações contemporâneas do ambiente dos negócios.

\section{REFERÊNCIAS}

ABBAS, K.; GONÇALVES, M. N.; LEONCINE, M. (2012) Os métodos de custeio: vantagens, desvantagens e sua aplicabilidade nos diversos tipos de organizações apresentadas pela literatura. Contexto, v. 12, n. 22, p. 145-159.

ATKINSON, A.A.; KAPLAN, R.S.; MATSUMURA, E.M,; YOUNG, S.M. (2015). Contabilidade Gerencial: informação para tomada de decisão e execução da estratégia. São Paulo, Editora Atlas.

BENDAPUDI, N.; LEONE, R. P. (2003) Psychological implications of customer participation in co-production. Journal of Marketing, v. 67, n. 1, p. 14-28.

CASAS, A.L. L. (2014) Cocriação de Valor: conectando a empresa com os consumidores através das redes sociais e ferramentas colaborativas. (2014). São Paulo: Atlas.

CASTELLS, M. (2016) A sociedade em rede. Tradução Roneide Majer, 17 edição. São Paulo: Paz e Terra. 


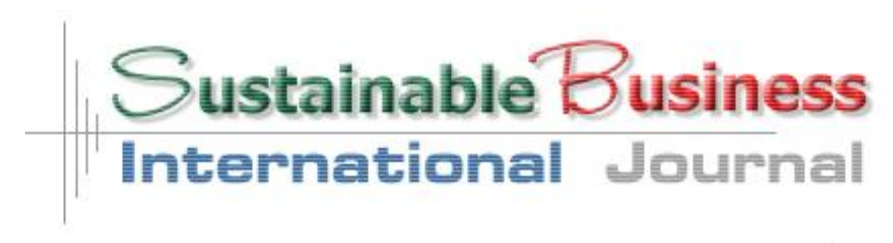

SBIJ87 - JULHO DE 2019 - ISSN 1807-5908

COElHO, C. U. F.; LINS, L dos S. (2010). Teoria da Contabilidade: abordagem contextual, histórica e gerencial. São Paulo: Atlas.

DIAS, E.A.; PADOVEZE, C.L. (2007). Os diferentes métodos de custeio e sua implicação na apuração de custo do produto: um estudo caso em empresa de graxas e óleos industriais. Revista Eletrônica Gestão e Sociedade. v.2, p.2-22.

DUBOIS. A. (2003) Strategic cost management across boundaries of firms. Industrial Marketing Management, [S.1.], v. 32, p. 365-374.

FASB CONCEPTS STATEMENT N 3.(1980) Elements for Financial Statements os Business Enterprises. FASB.

FISK, P. (2006) O gênio do marketing. Porto Alegre: Artmed.

FROW, P. (2008) Managing the co-creation of value. Journal of the Academy of Marketing in Science. v. 36, n 1. P. 83-96.

GOUILLART, F. (2010). Building the CoCreative Enterprise. Harvard Business Review, p.19.

GRÖNROOS, C.; RAVALD, A. (2011). Service as Business Logic: implications for Value Creation and Marketing. Journal of Service Management, v.22, n.1, p. 5-22.

GRÖNROOS, C.; VOIMA, P. (2013). Critical Service Logic: Making Sense of Value Creation and Co-creation. Journal of the Academy of Marketing Science, v.4, n.12, p. 133150.

HUSTON, L.; SAKKAB, N. (2006). Connect and develop, inside Procter \& Gamble's new model for innovation. Havard Business Review, mar. p.63-78.

JIAMBALVO, J. (2009).Contabilidade Gerencial. 3. ed. Rio de Janeiro: LTC.

IUDÍCIBUS, S. de.; MARTINS, E; GELBCKE, E.R.; SANTOS, A. Manual de contabilidade societária: aplicável a todas as sociedades. São Paulo: Atlas, 2007.

KAPLAN, R. S.; COOPER, R. (1998). Custo e desempenho: administre seus custos para ser mais competitivo. São Paulo: Futura.

KULMALA, H.I.; PARANKO, J.; UUSI-RAUVA, E. (2002). The role of cost management in network relationships. International Journal of Production Economics, [S.I.], v. 79, p.3343.

LOCKAMY, A.; SMITH, W. (2000). Target costing for supply chain management and selection. Industrial Management and Data Systems, United Kingdom, v. 100, n. 5 p. 201218.

MCCOLL-KENNEDY, R.; VARGO, S. L.; DAGGER, T. S.; SWEENEY, J. C.; VAN KARSTEREN, Y. (2012). Health care customer value cocreation practice styles. Journal of Service Research, v.15, n. 4, p.370-389.

MAGRETTA, J. (2012). Entendendo Michel Porter: guia essencial da competição e estratégia. Tradução Carlos Szlak. São Paulo: HSM editora.

MARKANTONIS, V.; MEYER, V.; SCHWARZE, R. (2012). Valuating the intangible effects of natural hazards: a review and evaluation of the cost-assessment methods. In European Society for Ecological Economics conference.

MARTINS, E. (2010). Contabilidade de Custos. 10a Edição. São Paulo: Ed. Atlas.

MILL, A. (2017). Economia: tudo o que você precisa saber. Tradução de Leonardo Abramowics. São Paulo: Ed. Gente. 


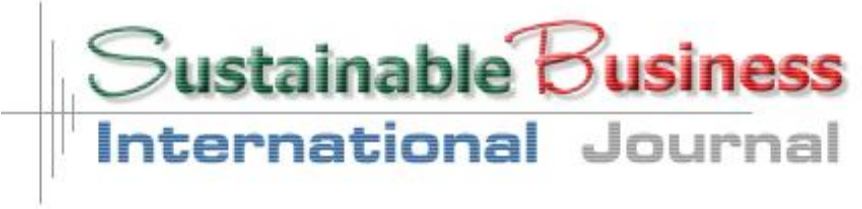

SBIJ87 - JULHO DE 2019 - ISSN 1807-5908

NAMBISAN, S.; NAMBISAN, P. (2008). How to profit from a better'virtual customer environment'. MIT Sloan management review, v. 49, n. 3, p. 53-70.

NAKAGAWA, M. (2012). Gestão Estratégica de Custos: Conceito, Sistemas e Implementação. 1. ed. 10. reimpr. São Paulo: Atlas.

PAYNE, A.F.; STORBACKA, K.; FROW, P. (2008). Managing the co-creation of value. Journal of the Academy of Marketing Science, v. 36, n. 1, p. 83-96.

PLEYER, S.; MARX JR, C. A. (2000). A convergência do software empresarial para o custeio baseado em atividades. Lições mundiais da Arthur Andersen em ABM. São Paulo: Futura.

PRAHALAD, C.K.; RAMASWAMY, V. (2004). Co-creating unique value with customers. Strategy e Leadership, v. 32, n. 3, p. 4-9.

PORTER, M.E. (1986). Estratégia Competitiva: técnicas para análise de indústrias e da concorrência. Tradução de Elizabeth Maria de Pinho Braga. $7^{a}$ ed. Rio de Janeiro: Campus.

REEVE, J. M.; FESS, P. E. (2003). Contabilidade Gerencial. Trad. André O. D. Castro. São Paulo: Thomson Learning, $463 \mathrm{p}$.

ROMASWAMY, V.; GOUILLART, F. (2010). A empresa co-criativa. Rio de Janeiro: Elsevier; São Paulo: Symnetics.

SLAVOV, T. N. B. (2013). Gestão Estratégica de Custos: uma contribuição para a construção de sua estrutura conceitual. 2012. 291 f. Tese (Doutorado em Controladoria e Contabilidade). Faculdade de Economia, Administração e Contabilidade da Universidade de São Paulo, São Paulo.

SMITH, A. (2000). A Riqueza das Nações: Das causas do aprimoramento das forças produtivas do trabalho. São Paulo. Editora Juruá, $1^{\text {a }}$ ed.

TAVARES, V.C.M. (2016) Práticas da experiência e do relacionamento nas abordagens da cocriação de valor e teoria dos stakeholders: um estudo de casos múltiplos em academias de ginástica em São Paulo capital. 211p. Dissertação de Mestrado apresentada ao Programa de Mestrado e Doutorado em Administração da Universidade Nove de Julho UNINOVE, São Paulo.

VARGO, S. L.; LUSCH, R. F. (2004). Evolving to a new dominant logic for marketing. Journal of Marketing, v.68, n.1, p.1-17.

WARREN, J.; REEVE, M.; FESS, P.E. (2001). Contabilidade Gerencial. 6 ${ }^{\text {aed. Tradutor }}$ André Castro. São Paulo: Pioneira Thomson Learnin..

ZAGO, A.; KYOKO, W.E. (2013). Dinâmica de stakeholders e cocriação de valor em museus: um olhar inicial. Revista Ibero Americana de Estratégia, vol. 12, núm. 2, abr-jun, p. 274-298. 